\title{
Development of second generation ethanol process based on xylose consumption using non-conventional and recombinant yeasts
}

\author{
Isabela Pereira ${ }^{1}$, Ângela dos Santos ${ }^{2}$, Davi Gonçalves ${ }^{2}$, Marcela Purificação ${ }^{2}$, Nick \\ Guimarães $^{1}$, Robson Tramontina ${ }^{3}$, Natalia Coutouné ${ }^{4}$, Eduardo Zanella ${ }^{2}$, Boris Stambuk ${ }^{2}$, \\ and Jaciane Ienczak ${ }^{5}$ \\ ${ }^{1}$ Universidade Federal de Santa Catarina Centro Tecnologico \\ ${ }^{2}$ Federal University of Santa Catarina \\ ${ }^{3}$ Universidade Estadual de Campinas \\ ${ }^{4}$ National Center for Research in Energy and Materials (CNPEM) \\ ${ }^{5}$ Universidade Federal de Santa Catarina
}

May 5, 2020

\begin{abstract}
Fermentation of the pentose fraction from hemicellulosic hydrolysate is an important challenge to be studied in second generation ethanol (E2G) production. In this sense, we have tested non-conventional (Scheffersomyces stipitis and Spathaspora passalidarum) and recombinant yeast strains (Saccharomyces cerevisiae recombinant MP-C5 and MP-C5H1) capable to uptake xylose with the aim to design a strategy for $\mathrm{E} 2 \mathrm{G}$ production. Growth tests in different carbohydrates (glucose, xylose, glucose + xylose and sucrose + xylose) have shown that the integration of xylose and sucrose presented better results for all yeast tested, and the co-fermentation of these sugars provided faster xylose consumption by S. cerevisiae recombinant. One the other hand, Sp. passalidarum do not present high performance of sucrose consumption in microanaerobic fermentation conditions and an intracellular invertase high activity was observed by this yeast. S. cerevisiae MP-C5H1 presented best performance for fermentation tests and a batch strategy with high cell density was designed. By this strategy was possible to achieve high ethanol yield $\left(0.48 \mathrm{~g} \mathrm{~g}^{-1}\right)$, titer $\left(53.7 \mathrm{~g} \mathrm{~L}^{-1}\right)$ and global ethanol productivity $\left(2.24 \mathrm{~g} \mathrm{~L}^{-1} \mathrm{~h}^{-1}\right)$.
\end{abstract}

\section{Hosted file}

Manuscript_Pereira et al., 2020.doc available at https://authorea.com/users/301118/articles/ 430923-development-of-second-generation-ethanol-process-based-on-xylose-consumptionusing-non-conventional-and-recombinant-yeasts 